eCommons@AKU

August 2005

\title{
Trends in hospital-based management of acute asthma from a teaching hospital in South Asia.
}

\author{
S F.HUSSAIN \\ Aga Khan University \\ MD. OMAR \\ Aga Khan University \\ H. ARI \\ Aga Khan University \\ S.R. SAMEERUDDIN \\ Aga Khan University \\ Ali Bin Sarwar Zubairi \\ Aga Khan University, ali.zubairi@aku.edu \\ See next page for additional authors
}

Follow this and additional works at: http://ecommons.aku.edu/pakistan_fhs_mc_med_med Part of the Pulmonology Commons

\section{Recommended Citation}

HUSSAIN, S. F., OMAR, M. D., ARI, H., SAMEERUDDIN, S. .., Zubairi, A., Khan, J. (2005). Trends in hospital-based management of acute asthma from a teaching hospital in South Asia.. International journal of clinical practice., 59(8), 912-916.

Available at: http://ecommons.aku.edu/pakistan_fhs_mc_med_med/318 
Authors

S F. HUSSAIN, M D. OMAR, H. ARI, S .R. SAMEERUDDIN, Ali Bin Sarwar Zubairi, and Javaid Khan 


\title{
Trends in hospital-based management of acute asthma from a teaching hospital in South Asia
}

\author{
S. F. HUSSAIN, M. D. OMAR, H. ARIF, S. R. SAMEERUdDIN, A. B. S. ZUBAIRI, J. A. KHAN \\ Section of Pulmonary and Critical Care Medicine, Aga Khan University, Karachi, Pakistan
}

\section{SUMMARY}

The aim of this study is to evaluate the hospital-based management of acute asthma in south Asia and to compare practices over a 10 -year period. Adult patients $(n=102)$ admitted at a teaching hospital with acute asthma were studied. Documentation of precipitating factors, family history and physical signs were inadequate in more than half of patients. Pulse oximetry was documented in 95 (93\%) patients, but peak flow monitoring was performed only in $50(49 \%)$ patients. Ten-year trend showed deterioration in history and physical examination skills, under use of peak flow readings, and poor pre-discharge instructions. Some aspects of improved care included frequent use of pulse oximeter, preference of inhaled over systemic bronchodilators and increased use of systemic steroids. Significant deficiencies were identified in hospital-based management of acute asthma. Most aspects of asthma care continued to fall short of asthma guidelines.

Keywords: Asthma; hospital-based management; trends; Pakistan

(C) 2005 Blackwell Publishing Ltd

\section{INTRODUCTION}

Asthma is a chronic inflammatory disease of the airways. Global Initiative for Asthma Program estimated that approximately 300 million people around the globe suffer from asthma (1). In the ISAAC study, there was a worldwide variation in the prevalence of asthma with 20 - to 60-fold difference between various centres (2). Highest prevalence was seen in developed countries, including the UK, Australia and New Zealand. Lowest prevalence was seen in Asian, African and eastern European centres. Asthma prevalence of $8 \%$ was recorded among Pakistani children. The incidence of asthma has been rising in many countries and asthma resulted in over 180,000 deaths annually (3). In the US, over 1.8 million visits to the emergency room (ER) were attributed to asthma, costing over $\$ 430$ million (4).

In a recent study from Pakistan, it was found that general medical practitioners did not generally follow asthma management guidelines (5). There was serious lack of knowledge about asthma medications coupled with misconceptions about inhaler therapy and dietary factors. Only 35\% of doctors prescribed corticosteroids for persistent asthma symptoms and great majority of doctors were not aware of treatment

Correspondence to:

Prof S. Fayyaz Hussain, Section of Pulmonary and Critical Care Medicine, Aga Khan University, PO Box 3500, Stadium Road, Karachi 74800, Pakistan

Tel.: + 922148594682

Fax: + 92214934294

Email: fayyaz.hussain@aku.edu; sfh_pulmonary@yahoo.co.uk options for persistent symptoms. Similarly, in an audit of hospital management of asthma in Pakistan, performed 10 years ago, several deficiencies were observed. These included deficiencies in assessing severity of asthma, recording of peak flow readings and teaching of inhaler techniques (6).

The aim of this study is to evaluate the hospital-based management of acute asthma in a teaching hospital of South Asia and to compare practices over a 10 -year period.

\section{METHODS}

All adult patients (aged 15 or over) with acute exacerbation of asthma, admitted through ER, between February 2003 and March 2004, were included in the study. Data were collected on demographic and clinical features, prior use of medications and investigations and management in ER. Details of ward management, readmission within $24 \mathrm{~h}$ of discharge and mortality were reviewed. Asthma was diagnosed on clinical features (episodic symptoms; recurrent wheeze, cough or dyspnea; associated allergic symptoms and family history, and presence of bilateral wheeze on admission), diminished peak flow readings and absence of other diseases that may mimic asthma (e.g. pulmonary oedema, pneumonia or pneumothorax). Patients who were current smokers or who had an established diagnosis of chronic obstructive pulmonary disease (COPD) were excluded from the study. Only one ex-smoker who had stopped smoking for over 10 years was included in the study.

In 1995 study, adult patients admitted with acute exacerbation of asthma, admitted through ER, between 1991 and 1993, were included. One hundred of 593 patients admitted 
during that period were randomly selected for the study. Inclusion and exclusion criteria were similar, and questionnaire was of similar format (documentation of clinical features, ER evaluation and management) allowing us to compare the practices over time.

The statistical package for social science (SPSS) (Release 10.0.5, standard version, copyright (C) SPSS; 1989-1999) was used for data analysis. The descriptive analysis was performed for demographic and clinical features. Results have been expressed as mean $\pm S D$ (or range) for continuous variables, and number (percentage) for categorical variables. Difference of the proportion was assessed by using Pearson's $\chi^{2}$ test; Fisher exact test was used when expected count was $<5$; p-value of $<0.05$ was considered statistically significant. All p-values were two-sided.

\section{RESULTS}

One hundred two patients, with acute exacerbation of asthma, were admitted from the ER during the study period. An additional four patients discharged themselves soon after initial ER treatment and were not included in the study.

Of the 102 patients, 27 (26\%) were men and 75 (74\%) were women. Their mean age was 53.88 years (range: $17-80$ ), with $76(75 \%)$ patients in the age group of $40-74$ years. The mean stay in the ER was $3.84 \mathrm{~h}$ (range: $1-8.5$ ) and duration of hospitalization was 3.75 days (range: 1-14). Pre-admission medications were taken by $78(75 \%)$ patients. Of these, 25 (32\%) were taking single, 36 (46\%) taking two and 17 (22\%) taking three or more medications. The trends in pre-admission medications over a 10-year period have been compared in Table 1. There was significant increase in the use of inhaled medications and decline in the use of systemic medications. In the present study, $71(70 \%)$ patients used inhaled therapy before admission, 31 combination of steroids and bronchodilators, 38 bronchodilators only and two steroids only.

The documentation of clinical features and peak expiratory flow rate (PEFR) monitoring has been summarized in Table 2. Precipitating factors and family history were documented in less than half of the patients. Important physical signs, including accessory muscles and inability to speak, were documented in less than a quarter of patients. When the results are compared with the findings in 1995, there was a decline in the documentation of physical signs. PEFR monitoring was performed more often but still documented only on $50(49 \%)$ ER patients and 38 (37\%) ward patients.

The salient aspects of investigations and management have been summarized and they have been compared with those of the study performed a decade ago (6) in Table 3. Pulse oximetry was documented in $95(93 \%)$ patients, whereas this facility was not routinely available 10 years ago. This resulted in a significant fall in the number of arterial blood gas (ABG) analyses performed. Chest radiograph continued to be performed on most patients.

In the ER, nebulizers were administered to 94 (92\%) patients; $55 \%$ receiving salbutamol alone and remaining in combination with ipratropium. All the patients were administered systemic steroids; $72 \%$ received intravenously. On the wards, $43(42 \%)$ received oral steroids only, the remaining intravenous followed by oral steroids. Frequencies of use of other medications remained unchanged. Antibiotics were prescribed to $59(58 \%)$ patients; indications were abnormal chest radiograph in $25 \%$, fever in $68 \%$, leucocytosis in $54 \%$ and sputum purulence in $47 \%$. Compared to previous study, there was a significant decrease in the use of intravenous theophylline from 68 to $4 \%$. Hypoxaemia was present in $17 \%$ of patients. None of the patients required mechanical ventilation and there was no mortality.

Out patient follow-up appointment was given to $95 \%$ with a $67 \%$ turnover. Readmission rate within $24 \mathrm{~h}$ of discharge was $1 \%$. Many aspects of discharge planning were poor including documentation of inhaler technique in only $7 \%$. Similarly, oral steroid was prescribed to $53 \%$ but inhaled steroid to only $3 \%$ and there was no formal documentation of self-management plan.

\section{DISCUSSION}

This study describes the trends in the management of acute asthma at a teaching hospital in South Asia. Although a number of improvements have been observed, this has occurred at the expense of deterioration in other parameters. History taking was insufficient on a number of important aspects. Similarly, less emphasis was placed on physical signs (e.g. inability to speak, use of accessory muscles and cyanosis),

Table 1 Ten-year trend in the use of pre-admission medications in patients admitted with acute asthma

\begin{tabular}{|c|c|c|c|}
\hline Pre-admission medications & 1995 (100 patients) (\%) & 2004 (102 Patients) (\%) & $p$-value \\
\hline Inhaled bronchodilator & 31 & 69 & $<0.0001$ \\
\hline Oral bronchodilator & 20 & 7 & 0.006 \\
\hline Inhaled steroid & 4 & 33 & $<0.0001$ \\
\hline Systemic steroid & 21 & 9 & 0.015 \\
\hline Antibiotic & 6 & 11 & Not significant \\
\hline Oral theophylline & 18 & 1 & - \\
\hline
\end{tabular}


Table 2 Ten-year trends in the documentation of history, examination and peak expiratory flow rate in patients admitted with acute asthma

\begin{tabular}{|c|c|c|c|}
\hline & \multicolumn{2}{|c|}{ Documentation } & \multirow[b]{2}{*}{ p-value } \\
\hline & $1995(\%)$ & $2004(\%)$ & \\
\hline \multicolumn{4}{|l|}{ History } \\
\hline Precipitating factor & 77 & 37 & $<0.001$ \\
\hline Previous attacks & 92 & 81 & 0.027 \\
\hline Family history & 39 & 40 & Not significant \\
\hline \multicolumn{4}{|l|}{ Physical signs } \\
\hline Pulse rate & 100 & 98 & Not significant \\
\hline Respiratory rate & 100 & 97 & Not significant \\
\hline Inability to speak & 60 & 22 & $<0.001$ \\
\hline Use of accessory muscles & 59 & 22 & $<0.001$ \\
\hline Cyanosis & 92 & 75 & 0.002 \\
\hline Wheeze & 100 & 96 & Not significant \\
\hline \multicolumn{4}{|l|}{ Peak expiratory flow rate } \\
\hline Monitoring in emergency room (ER) & 23 & 49 & $<0.001$ \\
\hline Monitoring in ward & 10 & 37 & 0.001 \\
\hline
\end{tabular}

which help us in assessing the severity of asthma attack at bedside. When we compare our findings with those of the previous study performed a decade ago (6), the documentation of physical signs had deteriorated over time. Similar results were found in an audit on assessment and management of acute bronchial asthma in the emergency department of a district hospital in Malaysia, which seriously affected their decision of admission and was responsible for a large number of relapses (7).

Ready availability of pulse oximeter in ER had resulted in the monitoring of oxygen saturation in $93 \%$ and this was accompanied with a significant decline in the number of ABG analyses. Use of peak flow meter to assess asthma severity had significantly improved with time but still remained low in ER (49\%) and on the wards (37\%). The discrepancy between the use of pulse oximetry and peak flow rate, despite both being performed by nurses in ER, could be related to the fact that oximetry was immediately performed on all patients presenting with pulmonary symptoms, but PEFR was only performed once a need to assess asthma was made by the attending doctor or nurse. Similar discrepancy was seen in Chicago asthma surveillance initiative project, where PEFR measurements, while common, were used less frequently than pulse oximetry (8). In Asian countries, several reports have highlighted the low use of PEFR. In Malaysia, PEFR were only documented in $14.5 \%$ of ER and $54.8 \%$ of ward notes (9). We have observed that none of the general practitioners use peak flow monitoring to assess asthma severity, despite treating patients with asthma exacerbations on a regular basis. This is supported by the findings in recent survey that the prescribing practices of general physicians in Pakistan did not generally conform to the national and international asthma guidelines (5). A number of studies have reported inadequate compliance with international guidelines in countries of Asia

Table 3 Investigations and treatment in patients admitted with acute asthma

\begin{tabular}{llll}
\hline & Documentation & & \\
\cline { 2 - 4 } & $1995(\%)$ & 2004 (\%) & P value \\
\hline Investigations & & & - \\
$\quad$ Pulse oximetry & 73 & 93 & $<0.001$ \\
Arterial blood gas (ABG) analyses & 85 & 46 & Not significant \\
Chest radiograph & & 84 & Not significant \\
Treatment & 99 & 92 & $<0.001$ \\
$\quad$ Nebulized bronchodilators & 68 & 4 & $<0.001$ \\
Intravenous theophylline & 69 & 100 & Not significant \\
Systemic steroids & 56 & 58 & - \\
$\quad$ Systemic antibiotics & - & 7 & Not significant \\
Pre-discharge management & 88 & 95 & \\
Inhaler technique reviewed & & \\
Follow-up appointment given & & & \\
\hline
\end{tabular}


Pacific region and Middle East (10,11). In Taiwan, differences in compliance were also observed between various hospitals (district general vs. regional centres) of the same country (12).

Less than $70 \%$ of the asthma patients, in our study, were on inhaled bronchodilators and less than a third on inhaled steroids before their asthma attack. Although there was a significant increase in the use of inhaled medications and a decline of oral medications over a 10-year period, there remained a room for improvement. Similar trends were seen in the pattern of drug prescribing in ER. Use of nebulized bronchodilators was seen in over $90 \%$ of patients in both studies, but there was a substantial decline in the use of intravenous theophylline and a significant increase in the use of systemic steroids. Antibiotics prescribing remained unchanged and unacceptably high, being used in more than $50 \%$ of patients. Overuse of antibiotics in the management of acute asthma has been observed both in the East (11) and in the West (13), but this issue has not been adequately addressed in many recent studies from Asia. In developing countries, where cost is a major concern, overprescribing would lead to more expensive regimen with a greater risk of side-effects.

One area of asthma management, which remained seriously underrecognized, was pre-discharge planning. Although outpatient appointments were given to most patients, inhaler technique was rarely documented before discharge. In a study from Kuwait, there was no documentation of discharge planning (11). In a study from Malaysia, poor discharge planning resulted in frequent readmission $(37 \%)$ of patients discharged from ER (7). In the Chicago asthma surveillance initiative, a marked decline was seen, between 1996 and 2000 , in instructions to inform patients what to do in the event of inability to attend their follow-up appointment (14).

Over a 10-year period, management of acute asthma in South Asia has improved in some aspects, but continues to fall short in many areas. Of particular concern were the declines in history and physical examination skills, underuse of peak flow readings and poor pre-discharge instructions to use asthma medications. Similar conclusions were noted in Chicago Study with improvement in some areas and worsening in others, but most aspects of asthma care continued to fall short of national asthma guidelines (14).

British Thoracic Society (BTS) guidelines are widely used for the management of acute severe asthma (15). Based on suggested items in BTS audit tool, some aspects of asthma care continued to fall short of guidelines. Peak expiratory flow reading assessment was made in only $49 \%$ of patients on admission and $37 \%$ received serial monitoring on the wards. Oral steroids were prescribed to $53 \%$, but a prescription of inhaled steroid on discharge was given to only $3 \%$. BTS guidelines recommend that, at the time of discharge, patients should be administered both oral and inhaled steroids in addition to bronchodilators. There was no formal documentation of self-management plan and this aspect needed urgent attention. Those aspects that were conforming to BTS audit tool included measuring $\mathrm{ABG}$ in patients with $\mathrm{SaO}_{2}$ below $90 \%(100 \%)$, administering systemic steroids in ER (100\%) and giving a follow-up appointment (95\%).

Continued medical education may help improve the dissemination of guidelines to the physicians, but it was not found to be sufficient in improving ER asthma care $(14,16)$. Development of a multidisciplinary asthma disease management programme in a large medical group practice in an urban area of USA was associated with a marked reduction in the rates of hospitalization and ER usage for asthma, as well as significant improvement in several essential processes of care (17). The disease management intervention included the development of a patient registry, a systematic approach to the assessment of asthma control by using the Asthma Therapy Assessment Questionnaire, case management and physician education. Each hospital should address its management deficiencies, behaviour of doctors and nurses and available resources to deliver cost-effective asthma care according to international guidelines.

In order to improve hospital management of acute asthma, we propose to (i) publish patient education material in local language to be given at the time of discharge; (ii) recruit a practice nurse to implement patient education, teach inhaler technique and document a self-management plan; (iii) organize teaching workshops for doctors and nursing staff; (iv) perform annual audit to monitor progress; (v) to improve deficiencies identified in annual audit.

\section{CONCLUSIONS}

Significant deficiencies exist in the hospital management of acute asthma in South Asia. Despite some advances over a 10year period, most areas of assessment and management fall significantly short of international asthma guidelines. Implementation of a multidisciplinary management programme may help us in improving the documentation and management of patients with acute asthma.

\section{REFERENCES}

1 Masoli M, Fabian D, Holt S, Beasley R et al. Global Initiative for Asthma (GINA) Program. The global burden of asthma: executive summary of the GINA Dissemination Committee report. Allergy 2004; 59: 469-78.

2 The International Study of Asthma and Allergies in Childhood (ISAAC) Steering Committee. Worldwide variation in prevalence of symptoms of asthma, allergic rhinoconjunctivitis, and atopic eczema: ISAAC. Lancet 1998; 351: 1225-32.

3 World Health Organization. Bronchial Asthma. Fact sheet No. 206. (Revised) January 2000. 
4 Smith DH, Malone DC, Lawson KA, Okamoto LJ, Battista C, Saunders WB. A national estimate of economic cost of asthma. Am J Respir Crit Care Med 1997; 156: 787-93.

5 Hussain SF, Zahid S, Haqqee R, Khan JA. Impact of asthma management guidelines on the prescribing practices of physicians in an Asian community. Int J Tuberc Lung Dis 2004; 8: 414-7.

6 Khan JA, Saghir S, Tabassum G, Husain SF. An audit on hospital management of bronchial asthma. J Pak Med Assoc 1995; 45: 298-300.

7 Nivedita N. An audit on the assessment and management of acute bronchial asthma in the accident and emergency department of a district hospital. Med J Malaysia 1996; 51: 89-92.

8 McDermott MF, Grant EN, Turner-Roan K, Li T, Weiss KB. Asthma care practices in Chicago area emergency departments. Chest 1999; 116: 167S-173S.

9 Kanesalingam R, Lu YS, Ong JJ et al. A study of admission criteria and early management of adult patients with acute asthma. Med J Malaysia 2003; 58: 587-93.

10 Lai CK, De Guia TS, Kim YY et al. Asthma insights and reality in Asia-Pacific Steering Committee. Asthma control in the AsiaPacific region: the Asthma Insights and Reality in Asia-Pacific Study. J Allergy Clin Immunol 2003; 111: 263-8.

11 Hijazi Z, Abdulmalek AK, Al-Taweel F, Al-Shareda S. Hospital management of children with acute asthma exacerbations in
Kuwait: adherence to international guidelines. Med Princ Pract 2002; 11: 126-30.

12 Lee PL, Luo JP, Shieh WM, Nien CT, Yang PC, Kuo SH. Hospital-based management of acute asthmatic exacerbation: an assessment of physicians' behavior in Taiwan. J Asthma 2001; 38: 575-83.

13 Gilberg K, Laouri M, Wade S, Isonaka S. Analysis of medication use patterns: apparent overuse of antibiotics and underuse of prescription drugs for asthma, depression, and CHF. J Manag Care Pharm 2003; 9: 232-7.

14 Lenhardt R, Malone A, Grant EN, Weiss KB. Trends in emergency department asthma care in metropolitan Chicago: results from the Chicago Asthma Surveillance Initiative. Chest 2003; 124: 1774-80.

15 British Thoracic Society, National Asthma Campaign Royal College of Physicians of London et al. The British guidelines on asthma management: 1995 review and position statement. Thorax 1997; 52 (Suppl.1): S1-21.

16 Chee CB, Wang SY, Poh SC. Department audit of inpatient management of asthma. Singapore Med J 1996; 37: 370-3.

17 Patel PH, Welsh C, Foggs MB. Improved asthma outcomes using a coordinated care approach in a large medical group. Dis Manag 2004; 7: 102-11.

Paper received November 2004, accepted February 2005 